\title{
The influence of SAPs on chloride ingress in cracked concrete
}

\author{
Tim Van Mullem ${ }^{1}$, Robby Caspeele ${ }^{1}$, and Nele De Belie ${ }^{1, *}$ \\ ${ }^{1}$ Magnel Laboratory for Concrete Research, Department of Structural Engineering, Faculty of Engineering and Architecture, \\ Ghent University, Technologiepark Zwijnaarde 60, B-9052 Gent, Belgium
}

\begin{abstract}
Super Absorbent Polymers (SAPs) have proven to be effective as a self-healing agent for regaining the liquid tightness of cracked concrete. This is due to their large swelling capacity which allows them to (partially) block cracks which are in contact with water or moisture. Additionally, they are able to release this water when the climate becomes drier, thereby promoting the autogenous healing capacity of the concrete matrix. The effect SAPs have on chloride migration into cracked concrete is still unknown. The swelling capacity of the SAPs might partially block the crack, but this does not necessarily mean that the chloride ingress into the crack is lower. Especially, since the porosity of concrete with SAPs is slightly higher when additional water is added to compensate for the loss in workability. This paper compares the chloride ingress in cracked mortar with and without SAPs. The specimens were saturated in a chloride solution during 1 or 5 weeks after which the chloride ingress could be visualised using silver nitrate. The specimens which healed prior to chloride saturation had a significantly lower chloride ingress. The SAPs were able to delay the chloride ingress, as well as limit the influence of the crack on the chloride ingress.
\end{abstract}

\section{Introduction}

Concrete is a brittle material with a low tensile strength. As a result, it is prone to cracking. Cracks can be the result of the structure being subjected to shear, bending, tension or torsion resulting from either direct loading or restrained or imposed deformations. Additionally, cracks can also be formed due to e.g. plastic shrinkage and expansive action of corroding steel.

The formed cracks are a preferential pathway for the ingress of harmful substances, especially chloride ions. Cracks often cross the structural tensile reinforcement, and in consequence chloride ions can reach the steel reinforcement directly, immediately starting chloride induced corrosion.

In order to prevent an untimely failure of the structure, the cracks have to be repaired. Yet, manual repair of cracks is costly as a result of: specific repair products, skilled labour and economic loss due to downtime of the structure. Additionally, the locations where repair is needed are often not easily accessible. Self-healing concrete is a possible solution which can save money over the lifetime of a structure. When the concrete cracks, the concrete will repair itself without the need for manual repair.

A lot of research has already been performed on the influence of cracks on chloride ingress $[1,2]$. However, the influence of self-healing on chloride ingress is scarcely reported in the literature. Most data can be found for encapsulated polymers: Maes et al. [3], Van den Heede et al. [4], and Van Belleghem et al. [5] investigated the effect of adding glass capsules filled with polyurethane on chloride resistance. Erşan et al. [6] studied the influence of nitrite producing bacteria on chloride ingress indirectly by investigating reinforcement bar corrosion.

Superabsorbent polymers (SAPs) are another type of healing agent used in self-healing concrete. [7, 8]. As they come into contact with water they swell and immediately seal the crack. The water that the SAPs absorb can be released over time during dry conditions, thereby stimulating the intrinsic autogenous healing capacity [9]. Up until now, their influence on chloride resistance has only been studied for uncracked concrete $[10,11]$. If no additional mixing water is added, addition of SAPs can result in a lower chloride ingress.

This research investigates the influences of SAPs on the transport of chloride ions in cracked mortar. Prior to the transport tests, the ability of the SAPs to seal and heal cracks was investigated by a water permeability test. The variability on these results is often large, partly due to the variability of the crack width between different specimens. To reduce the variability of the crack width, cracked specimens were manufactured using an active crack width control technique [12]. For chloride ingress, a distinction is made between specimens which were cracked and healed prior to chloride diffusion and specimens which were cracked and were not healed. After a saturation period of 1 or 5 weeks, cracked and uncracked specimens were sawn and the chloride ingress was visualised by spraying silver nitrate $\mathrm{AgNO}_{3}$ on the sawn surface. 


\section{Materials}

\subsection{Super Absorbent Polymers}

The type of SAP which was used in this study was FlosetTM 27 CC. It is commercially available from the company Floerger SNF. This type of SAP is a cross-linked copolymer of acrylamide and acrylate. The particle size was below $600 \mu \mathrm{m}$.

\subsection{Mortar composition}

For each test two different mortars were made: a reference mortar (REF) and a mortar containing SAPs (SAP).

\subsubsection{Water permeability}

To test the sealing efficiency, standard mortar prisms with dimensions of $40 \mathrm{~mm}$ by $40 \mathrm{~mm}$ by $160 \mathrm{~mm}$ were made. The mortar was made with a cement type CEM I $42.5 \mathrm{~N}$ and a standardised sand $0 / 2$. The sand to cement ratio was equal to 3 and the water to cement ratio was equal to 0.5 . The mixing procedure of EN 196-1 was followed.

For the mortar containing SAP, 1\% of SAP was added with respect to the weight of cement. To obtain a comparable workability between the REF and SAP series, $20 \mathrm{~g}$ of water was added per gram of SAP. The mixing procedure was identical to the one of the REF series, except for 30 s of dry mixing the cement, the sand, and the SAPs.

\subsubsection{Chloride ingress}

For testing the chloride ingress, cylinders with a diameter of $100 \mathrm{~mm}$ and a height of $200 \mathrm{~mm}$ were cast. The mortar mix composition for the specimens used to test the chloride ingress was similar to the mortar mix composition for the specimens used to test the sealing efficiency. The sand to cement ratio was equal to 3 and the water to cement ratio was equal to 0.5 . The cement which was used was a CEM I 52.5 N. Due to the larger dimensions of the specimens sand $0 / 4$ was used. The dry components were mixed for $1 \mathrm{~min}$, then water was added and the mixture was mixed for another $2 \mathrm{~min}$.

For the mortar containing SAP, $1 \%$ of SAP was added with respect to the weight of cement. $24 \mathrm{~g}$ of water was added per gram of SAP to obtain a comparable workability between the REF and SAP series. The SAP particles were mixed together with the dry components. The rest of the mixing procedure was identical to the REF mixture.

\section{Methods}

\subsection{Water permeability}

The water permeability of cracked specimens is usually measured before and after healing. The accuracy of permeability tests is strongly influenced by variations of the crack width. In order to have the highest accuracy possible, an active crack width control technique was used to manufacture cracked specimens exhibiting a low variability of their crack width. Subsequently, a water flow test was used to test the permeability. This method of controlling the crack width actively before performing a water flow test has already been used previously [12, 13]. From the results of the water flow test it was possible to calculate different sealing efficiencies.

\subsubsection{Active crack width control technique}

Unreinforced mortar specimens $\left(40 \times 40 \times 160 \mathrm{~mm}^{3}\right)$ were made with a cast-in hole $(\varnothing 5 \mathrm{~mm})$ positioned with its centre $1.5 \mathrm{~cm}$ from the bottom side. After curing, one side of the hole of the specimens was slightly enlarged and provided with a tube in order to connect the specimen to the water flow setup. The other side of the hole was sealed using silicone. Additionally, a Carbon Fibre Reinforced Polymer (CFRP) laminate (PC CARBOCOMP UNI from the company TRADECC) was glued on the top side of the specimens using epoxy resin. At an age of 28 days the specimens were cracked in a three-point bending setup. The CFRP laminate at the top did not act as reinforcement but guaranteed that the two halves of the specimens remained connected upon crack formation. However, due to the lack of tensile reinforcement, the crack between the two halves of the specimens was too big. To reduce the crack width a screw jack was mounted on the bottom of the specimens which allowed the application of a force to push both halves of the specimens back together. By iteratively applying more force and measuring the crack width, the desired crack width of $150 \mu \mathrm{m}$ at the bottom side could be reached with a good accuracy in each specimen. Fig. 1 shows a specimen for which the crack width was restrained using the described active crack width control technique.

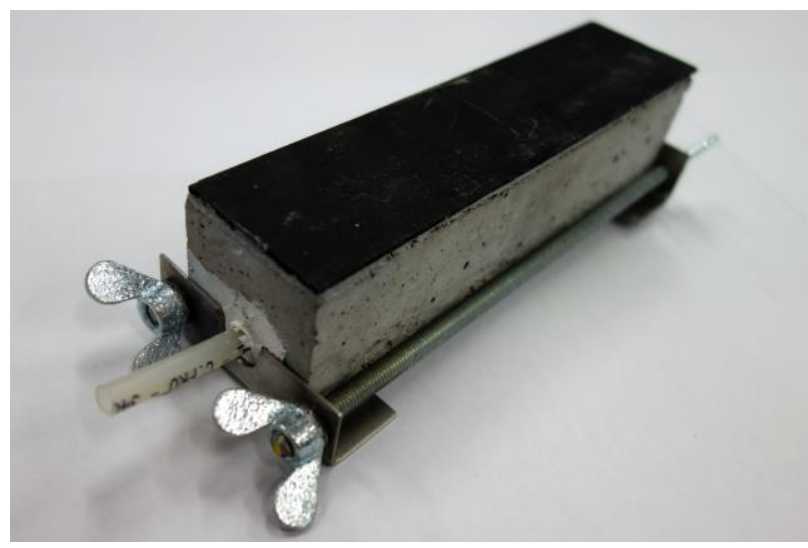

Fig. 1. Specimen for which the crack width was restrained using an active crack width control technique.

\subsubsection{Water flow test}

After cracking and subsequent restraining of the crack widths, the crack at the sides of the specimens was sealed, thus only leaving the crack at the bottom side 
unsealed. The specimens were then saturated for 2 days in demineralised water. After the saturation period, the tube of the specimens was connected to the test equipment, see Fig. 2. Via this tube, a constant water head of $50 \pm 2 \mathrm{~cm}$ was applied on the specimens. Water leaking out of the specimens through their crack was captured in a container which was mounted on an electronic balance which recorded the weight in function of time. The weight was recorded for a minimum of 5 min out of which an average water flow $Q$ could be determined in $\mathrm{g} / \mathrm{min}$.

After the initial water flow test the specimens were placed for 14 days in wet/dry cycles (12 h wet/ $12 \mathrm{~h}$ dry). They were then saturated for 2 days and tested again in the water flow setup. Finally, they were placed back in the wet-dry cycles for 14 days and after 2 days of saturation they were assessed in another water flow test.

After this water flow test, the specimens were tested at higher water pressures. In order to do this the connection to the open reservoir at a height of $50 \mathrm{~cm}$ was replaced by a connection to a pressure vessel. For 2 min the specimens were tested at a pressure of 1 bar, after which they were tested for $2 \mathrm{~min}$ at 2 bar. Finally, the specimens were again tested at a pressure of $50 \mathrm{~cm}$ for $5 \mathrm{~min}$.

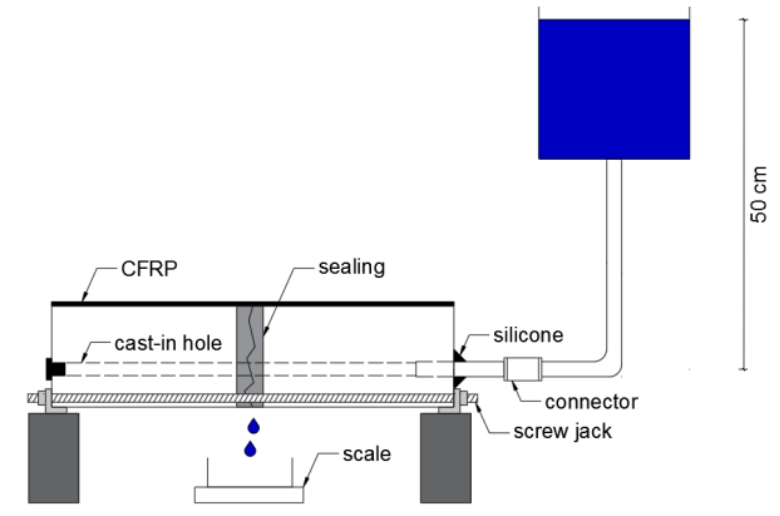

Fig. 2. Water flow setup (adapted from [12]).

\subsection{Chloride ingress}

The chloride ingress was tested on both REF and SAP mixtures. Half of them underwent prior healing before coming into contact with the chloride solution. So, in total, 4 series were tested: REF (not healed), SAP (not healed), REF (healed), and SAP (healed).

\subsubsection{Brazilian splitting}

Mortar specimens with a diameter of $100 \mathrm{~mm}$ and a height of $200 \mathrm{~mm}$ were sawn so that 3 disc specimens with a diameter of $100 \mathrm{~mm}$ and a height of $50 \mathrm{~mm}$ were obtained (the top and bottom part of the cylinders were thrown away). At an age of 28 days, the discs were completely cracked in a Brazilian splitting test. Subsequently, the two halves of a specimen were tied back together using metal straps. To create a specific crack width silicon sheets with a thickness of $100 \mu \mathrm{m}$ were placed at the outer ends. These silicon sheets acted as spacers. In this way the crack length was reduced from a nominal length of $100 \mathrm{~mm}$ to a nominal length of $70 \mathrm{~mm}$.

After this, the lateral surface and one of the circular surfaces was coated. This way, only one circular surface remained free of coating.

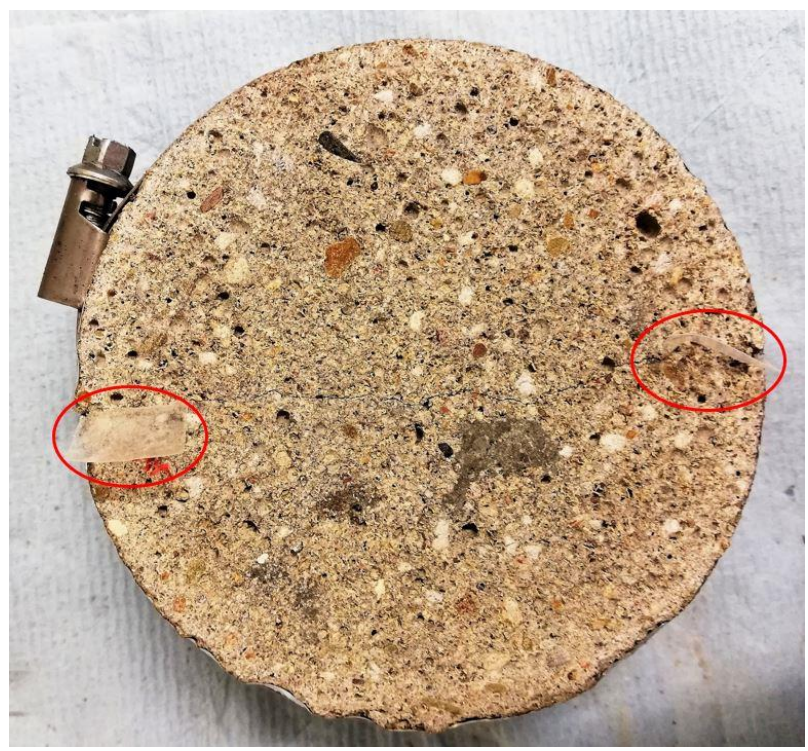

Fig. 3. Disc specimen (diameter of $100 \mathrm{~mm}$ and a height of $50 \mathrm{~mm}$ ) tied back together using metal straps with silicon sheets in the crack as spacers. The silicon sheets protruding out of the crack are highlighted by the red ellipses.

\subsubsection{Chloride saturation}

The 2 series which underwent healing prior to chloride saturation (REF (healed), and SAP (healed)) were placed for 28 days in wet-dry cycles (12 h wet/ $12 \mathrm{~h}$ dry), similar to the total healing period of the specimens used to test the sealing efficiency, see section 3.1.2. To obtain a similar saturation degree between the healed specimens which were placed in wet-dry cycles and the unhealed specimens, all specimens were saturated for 2 days in water prior to being saturated in the chloride solution.

The chloride solution had a $\mathrm{NaCl}$ concentration of $150 \mathrm{~g} / \mathrm{l}$. Each series was placed in a separate container. The ratio between the total exposed area of all specimens in a container in $\mathrm{cm}^{2}$ and the volume of exposure liquid in $\mathrm{dm}^{3}$ was equal to 60 . Every week the solution was stirred. The temperature throughout the test was equal to $20^{\circ} \mathrm{C}$.

After 7 days ( 8 days for SAP (healed)) and 35 days (36 days for REF (not healed)) 3 cracked and 3 uncracked specimens were removed from the chloride solution to determine the chloride ingress. For each series also 3 uncracked specimens were removed after 14 days ( 15 days for REF (not healed)).

\subsubsection{Chloride ingress by colour change boundary}

To determine the chloride ingress, the disc specimens were sawn perpendicular to their crack. The sawing was executed dry in order not to flush out any of the 
chlorides. After sawing, one sawn half was sprayed with $\mathrm{AgNO}_{3}$ (concentration of $0.1 \mathrm{~mol} / \mathrm{l}$ ). A line was drawn at the colour change. The chloride ingress perpendicular to the exposed surface was measured every $5 \mathrm{~mm}$ starting from the crack.

\subsection{Optical microscopy}

An optical crack microscope (Leica S8APO mounted with a DFC295 camera) was used to measure the crack width of both the specimens used for testing the sealing efficiency as well as the specimens used for testing the chloride ingress. For each crack three locations were chosen which were representative for the studied crack. For each location, 4 to 5 measurements of the crack width were performed. The crack widths reported in this paper are the average of all the measurements done at the three locations.

\section{Results and discussion}

\subsection{Sealing efficiency}

\subsubsection{Crack width measurement}

After cracking and subsequent active crack width control, the crack width was recorded for all prismatic specimens. Table 1 gives the mean crack width, as well as the standard deviation, of each specimen. The mean crack width $\mu$ of the REF series is nearly identical to the mean crack width of the SAP series $(154 \mu \mathrm{m}$ for REF and $153 \mu \mathrm{m}$ for SAP). This similarity is a result of the active crack width control technique. This also explains why the difference between the maximum and the minimum crack width is only $10 \mu \mathrm{m}$ for the REF series and $23 \mu \mathrm{m}$ for the SAP series. In the literature, far wider acceptable crack width ranges have been reported e.g. $40 \mathrm{~mm} \mathrm{[14]} \mathrm{and} 50 \mathrm{~mm} \mathrm{[15]} \mathrm{(both} \mathrm{for} \mathrm{crack-width-}$ controlled 3-point bending). While still acceptable, it should be noted that the standard deviation $\sigma$, and subsequently the coefficient of variance COV of the SAP series is approximately 2 times larger than for the REF series.

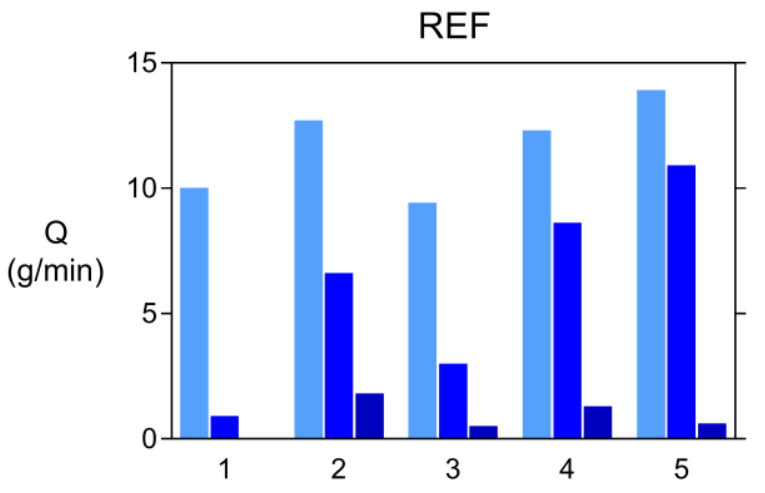

Table 1. Mean crack width $\mathrm{w}(\mu \mathrm{m})$ and standard deviation $\sigma$ $(\mu \mathrm{m})$ of 5 REF specimens and 6 SAP specimens used to investigate the sealing efficiency.

\begin{tabular}{cccccc}
\hline & \multicolumn{2}{c}{ REF } & & \multicolumn{2}{c}{ SAP } \\
\cline { 2 - 3 } \cline { 5 - 6 } & $\mathrm{w}$ & $\sigma$ & & $\mathrm{w}$ & $\sigma$ \\
\hline 1 & 151 & 12.8 & & 159 & 10.5 \\
2 & 159 & 21.4 & & 141 & 8.2 \\
3 & 157 & 17.7 & & 152 & 11.4 \\
4 & 149 & 15.6 & & 164 & 15.0 \\
5 & 153 & 10.4 & & 147 & 22.5 \\
6 & & & & 156 & 15.7 \\
\hline$\mu$ & 154 & & & 153 & \\
$\sigma$ & 4.2 & & 8.3 & \\
COV & $2.8 \%$ & & $5.4 \%$ & \\
\hline
\end{tabular}

\subsubsection{Sealing efficiency}

After the crack width was measured, the specimens were saturated for 2 days in demineralized water, after which an initial water flow test was performed on them. After 14 and 28 days of healing in wet-dry conditions, the water flow test was executed again. Fig. 4 shows the recorded flow $Q$ at these 3 different moments in time for both the REF and the SAP series. The water flow of the SAP specimens is clearly lower than the water flow of the REF specimens for all three considered times.

SAPs immediately absorb water the moment they come in contact with it. This allows them to swell and (partially) close the crack. This immediate sealing $S E_{\text {imm }}$ with reference to the REF specimens can be evaluated using equation 1 [14]:

$$
S E_{\text {imm }}=100 \% *\left(Q_{R E F, \text { initial }}-Q_{S A P, \text { initial }}\right) / Q_{R E F, \text { initial }}
$$

in which $Q_{R E F \text {, initial }}$ is the average initial flow of the REF specimens in $\mathrm{g} / \mathrm{min}$ and $Q_{S A P}$, initial is the average initial flow of the SAP specimens in $\mathrm{g} / \mathrm{min}$. The use of the averages is required since results from different specimens are used in this equation. Gruyaert et al. [14] state that the averages can only be used if the crack widths of all specimens are comparable. For an intended crack width of $150 \mu \mathrm{m}$ they propose a crack width range from $130 \mu \mathrm{m}$ until $170 \mu \mathrm{m}$. All studied specimens are in this range, see Table 1 . The immediate sealing $S E_{\text {imm }}$ is equal to $31.2 \%$ (with $Q_{R E F, \text { initial }}$ equal to $11.6 \mathrm{~g} / \mathrm{min}$ and $Q_{S A P, \text { initial }}$ equal to $7.9 \mathrm{~g} / \mathrm{min}$ ).

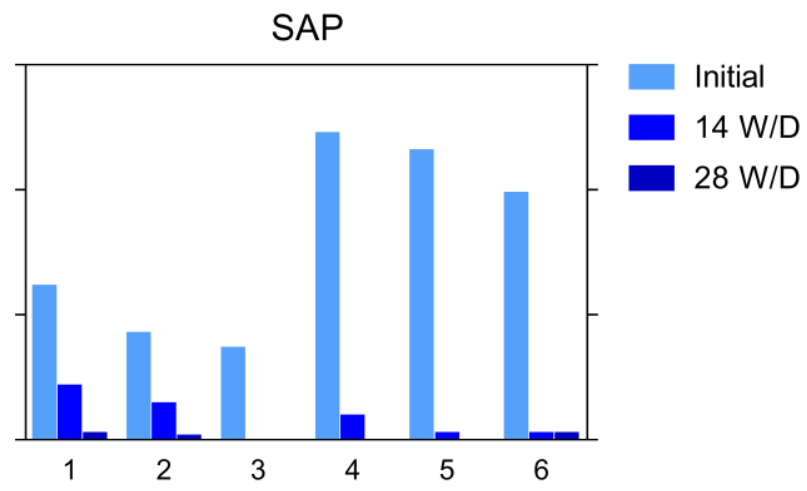

Fig. 4. Water flow $Q$ before, after 14 and after 28 wet/dry cycles for 5 REF specimens and 6 SAP specimens. 
By placing the specimens in wet-dry cycles they undergo a continuous process of hydration and dehydration. During dry periods, the SAP particles release the water that they have absorbed during the wet period. As a result of this the SAP specimens are wet much longer than the REF specimens.

It is possible to calculate the sealing efficiency as a consequence of the wet-dry cycles $S E_{W / D}$ by using equation 2 [14]:

$$
S E_{W / D}=100 \% *\left(Q_{\text {initial }}-Q_{\text {healed }}\right) / Q_{\text {initial }}
$$

in which $Q_{\text {initial }}$ is the average initial flow in $\mathrm{g} / \mathrm{min}$ and $Q_{\text {healed }}$ is the average flow in $\mathrm{g} / \mathrm{min}$ after 14 or 28 wet-dry cycles. To calculate $S E_{W / D}$ for the REF series, respectively SAP series, both $Q_{\text {initial }}$ and $Q_{\text {healed }}$ of the REF series, respectively SAP series, are used. $S E_{W / D}$ calculated out of the flow after 14 or 28 wet-dry cycles is given in Table 2. $S E_{28} W / D$ of the SAP specimens is very high $(99.0 \%)$, although it should be noted that $S E_{28}$ W/D for the REF specimens is also quite high (93.6\%). The effect of the SAPs is more clearly visible when comparing the sealing efficiency after 14 wet-dry cycles $S E_{14 W / D}: 89.9 \%$ for SAP against $48.9 \%$ for REF. These results show that the mortar containing SAPs can seal its cracks which are subjected to wet-dry cycles quicker than the REF mortar.

Table 2. Sealing efficiency due to wet-dry cycles after 14 days $S E_{14 W / D}$, respectively 28 days $S E_{28 W / D}$, for both the REF and the SAP series.

\begin{tabular}{lcc}
\hline & REF & SAP \\
\hline$S E_{14 W / D}$ & $48.9 \%$ & $89.9 \%$ \\
$S E_{28 \text { W/D }}$ & $93.6 \%$ & $99.0 \%$ \\
\hline
\end{tabular}

After the completion of the wet-dry healing cycles, it is possible to also calculate the total sealing coefficient $S E_{t o t}$ of the SAP specimens, which is a combination of immediate sealing and sealing due to healing:

$$
S E_{\text {tot }}=100 \% *\left(Q_{R E F, \text { initial }}-Q_{S A P, \text { healed }}\right) / Q_{R E F, \text { initial }}
$$

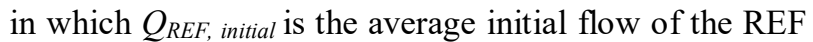
specimens in $\mathrm{g} / \mathrm{min}$ and $Q_{S A P}$, healed is the average flow of the SAP specimens in $\mathrm{g} / \mathrm{min}$ after 28 wet-dry cycles. Note that $Q_{S A P}$, healed can be replaced by an equivalent $Q_{R E F \text { healed }}$ of the REF series to calculate the total sealing coefficient $S E_{\text {tot }}$ of the REF series, but that equation (3) then becomes identical to equation (2). After all, REF series do not have an immediate sealing behaviour and as a consequence their total sealing only arises from the healing in the wet-dry cycles. In other words, $S E_{t o t}$ is equal to $S E_{28 \text { W/D }}$ for the REF series.

The total sealing $S E_{\text {tot }}$ of the SAP series is equal to $99.4 \%$, as opposed to $93.6 \%$ for the REF series. Half of the SAP specimens had a flow $Q$ equal to $0 \mathrm{~g} / \mathrm{min}$ after the 28 wet-dry cycles, and the other half had a flow which was lower than $0.2 \mathrm{~g} / \mathrm{min}$, see Table 3 . In comparison, only one REF specimen had sealed perfectly, while the other specimens still had a flow $Q$ between 0.35 and $1.70 \mathrm{~g} / \mathrm{min}$ after healing.
It can be concluded that, aside from promoting a faster sealing of cracks, SAPs also result in a more complete sealing of cracks. They stimulate the intrinsic autogenous healing capacity of mortar by increasing the availability of water in dry conditions allowing for further hydration and calcium carbonate precipitation [9].

After healing of the cracks, the strength of the healed products sealing the cracks was tested under higher water pressures. These tests at higher water pressures were executed immediately after the normal water flow test after 28 wet-dry cycles. After the tests at higher water pressures, the flow was measured again in a normal water flow setup at a water head of $50 \mathrm{~cm}$. The results of these 4 water flow tests is given in Table 3 . Out of the 3 SAP specimens that had a perfect sealing after 28 wet-dry cycles, 2 were able to resist a water pressure of 1 bar. The other specimen exhibited a very small flow $(0.05 \mathrm{~g} / \mathrm{min})$. However, the sealing of all these specimens failed at 2 bar. For the REF series there was only 1 specimen that was perfectly sealed after 28 wet-dry cycles. This specimen was not able to resist a water pressure of 1 bar.

Table 3. Water flow $Q$ in $\mathrm{g} / \mathrm{min}$ after 28 wet-dry cycles measured at a water pressure of 0.05 bar, 1 bar, 2 bar and finally 0.05 bar again.

\begin{tabular}{ccccc}
\hline & \multicolumn{4}{c}{$Q(\mathrm{~g} / \mathrm{min})$} \\
& 0.05 bar & 1 bar & 2 bar & 0.05 bar \\
\hline REF 1 & 0.00 & 2.79 & 4.91 & 0.51 \\
REF 2 & 1.70 & 4.21 & 8.50 & 0.05 \\
REF 3 & 0.35 & 12.40 & 19.58 & 0.26 \\
REF 4 & 1.17 & 25.09 & 50.44 & 2.52 \\
REF 5 & 0.48 & 5.75 & 8.61 & 0.40 \\
\hline SAP 1 & 0.17 & 25.73 & 91.18 & 4.67 \\
SAP 2 & 0.12 & 14.62 & 122.94 & 4.08 \\
SAP 3 & 0.00 & 0.00 & 1.53 & 0.02 \\
SAP 4 & 0.00 & 0.05 & 79.00 & 3.95 \\
SAP 5 & 0.00 & 0.00 & 59.74 & 3.80 \\
SAP 6 & 0.16 & 1.18 & 2.32 & 0.22 \\
\hline
\end{tabular}

Comparing the results of both series, it is evident that the SAP series performs the best under a water pressure of 1 bar as a result of the 3 specimens which still had a (nearly) perfect sealing at this water pressure. At a pressure of 2 bar the REF specimens performed better; 4 out of 6 SAP specimens had a higher flow than any of the REF specimens. It could be seen with microscopic images made after testing that some of the SAP particles had been pushed out near the crack. At other locations it was the healing product which was pushed out by the high pressures. It is possible that the formed crystals in the SAP specimens were less strong as a result of their faster formation; as the cracks heal quicker, less carbon dioxide is able to enter the crack, hence reducing the impact of the carbonation reaction.

Although the sealing was broken in many specimens due to the high water pressures, it appears that the water 
which leaked out of the crack at the end of the tests (when the specimen was subjected again to a water head of $50 \mathrm{~cm}$ for $5 \mathrm{~min}$ after testing at 1 and 2 bar) was at least not higher than the water that leaked out during the initial water flow before healing, see Fig. 4. Thus, the healing was only damaged partially due to the high pressure.

\subsection{Chloride ingress}

\subsubsection{Uncracked specimens}

At approximately 1 week, 2 weeks, and 5 weeks, three uncracked specimens of each series were removed from the chloride bath. Fig. 5 shows the chloride ingress for each series. When comparing specimens which underwent the same healing cycle (healed or not healed), the chloride ingress in the SAP specimens is clearly larger than in the REF specimens. It has been reported in

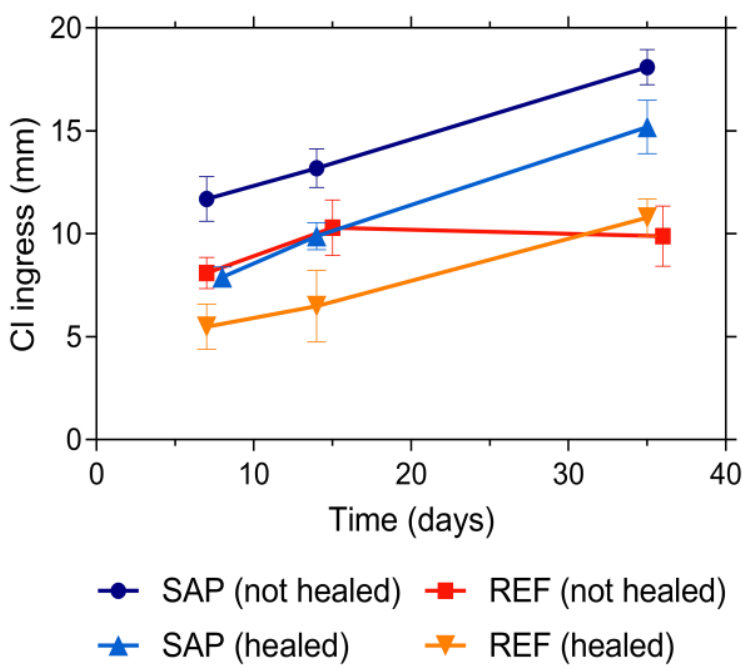

Fig. 5. Chloride ingress in uncracked REF and SAP specimens, respectively subjected and not subjected to wet-dry cycles. Error bars represent 2 times the standard deviation. literature that the amount of air voids in mortars containing SAPs (where additional water was added to compensate for a loss of workability) is higher than in reference mortars [16] thereby allowing the chloride ions to migrate quicker through the matrix. When comparing specimens with the same mortar composition (REF or SAP), the specimens subjected to healing cycles exhibit a lower chloride ingress (except for the REF specimens at 5 weeks for which the chloride ingress is comparable). The lower chloride ingress for the healed samples can be explained by a densification of the mortar matrix as a result of the healing regime.

\subsubsection{Unhealed specimens}

The average crack width of the REF (not healed) series, respectively SAP (not healed) series, was equal to $117 \mu \mathrm{m}$ (COV 9.9\%), respectively $153 \mu \mathrm{m}$ (COV 8.1\%). The crack width of the SAP series is clearly larger than the crack width of the REF series. This difference might influence the chloride migration, although it should be reported that Jin et al. [17] assumed in the development of a simplified calculation model that the chloride ion concentration in the crack is equal to the solution for crack widths larger than $100 \mu \mathrm{m}$.

Fig. 6 shows the chloride ingress after 1 week and 5 weeks of contact with the chloride solution for the REF, respectively SAP, series. The chloride ingress after 1 week of exposure is quite similar. The chloride ingress away from the crack is slightly bigger for the SAP series, as could be expected based on section 4.2.1. The fact that the chloride ingress at the location of the crack is similar means that the immediate sealing effect of the SAPs is not sufficient to prevent an ingress of chlorides. The immediate sealing reported in section 4.1.2 was $31.2 \%$, meaning that the crack was not completely sealed. Additionally, it should be pointed out that the cracks in the water permeability specimens have a triangular shape. The crack width will thus be smaller than the intended crack width of $150 \mu \mathrm{m}$ (comparable to the crack width of the uniform cracks in the SAP specimens used for chloride ingress) at the location of
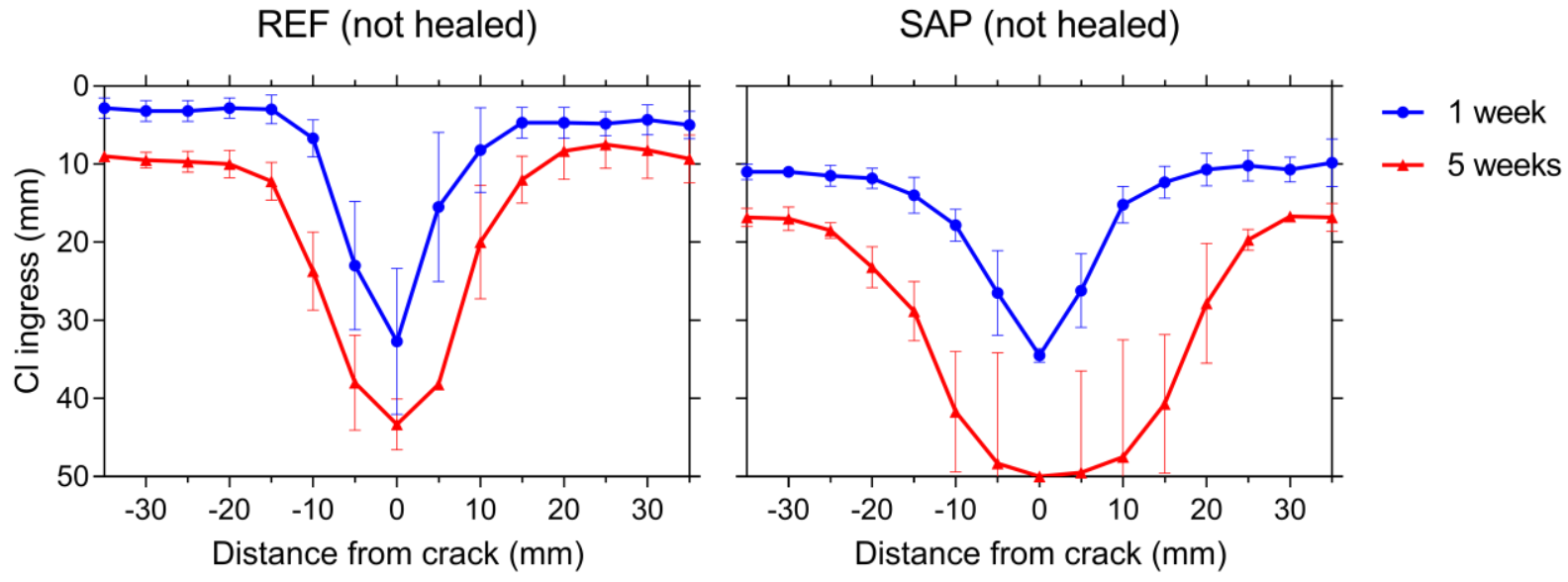

Fig. 6. Chloride ingress after 1 week and 5 weeks of saturation in a chloride solution of REF and SAP specimens which were not healed prior to contact with the chloride solution. 
the hole where the water is introduced into the specimen during water flow testing. As a result of the incomplete sealing of the cracks, the chloride ions were able to penetrate into the crack.

The chloride ingress after 5 weeks is more severe for the SAP series than for the REF series. For the SAP series the chloride ions have migrated through the entire height of all the specimens, while this was not the case for any of the REF specimens. Additionally, the chloride front is much wider around the crack for the SAP specimens than for the REF specimens. Similar as for the uncracked specimens this can be caused by a higher content of air voids.

\subsubsection{Healed specimens}

Immediately after cracking and before healing, the average crack width of the REF (healed) series, respectively SAP (healed) series, was equal to $107 \mu \mathrm{m}$ (COV 16.3\%), respectively $134 \mu \mathrm{m}$ (COV 8.1\%). These two averages are more or less equal to one another (effective significance level of $1.1 \%$ ).

Fig. 7 shows the chloride ingress after 1 week and 5 weeks of contact with the chloride solution for the REF, respectively SAP, series which were healed in wet-dry cycles prior to contact with the chloride solution. The beneficial influence of the healing regime is clearly evident by comparing these results to the results of the unhealed specimens.

After only 1 week of contact with the chloride solution, the chloride ingress in the healed SAP specimens is distinctly lower than in the healed REF specimens. After 5 weeks, the chloride ingress in the REF specimens is nearly unchanged. At the location of the crack the chloride ingress for both the REF and the SAP series is comparable. However, it should be noted that for the SAP series there was one specimen which had a much larger chloride ingress at the crack than the other two specimens which were analysed $(39 \mathrm{~mm}$ of chloride ingress from the exposure surface at the location of the crack versus $29 \mathrm{~mm}$ and $24 \mathrm{~mm}$ ). Notwithstanding the equal average chloride ingress at the crack, the influence of the crack seemed to be smaller for the SAP series than for the REF series; a constant chloride ingress was obtained much closer to the crack for the SAP series than for the REF series.

It can thus be concluded that adding SAPs to mortar which is allowed to heal prior to coming in contact with chloride ions results in a lower chloride ingress. At early ages the chloride penetration reduces and at later ages the influence of a crack on the chloride ingress reduces. This beneficial effect is a result of the stimulating effect SAPs have on the autogenous healing which results in a sealing of the cracks, as was also explained in section 4.1.2.

\section{Conclusion}

In this study the effect of SAPs on the chloride ingress in cracked mortar was studied. The following conclusions can be drawn:

- SAPs promote a faster and more complete sealing of cracks;

- Up until a water pressure of 1 bar the sealing of SAP specimens is better than the sealing of REF specimens, but at a water pressure of 2 bar healing products and SAP particles are pushed out;

- When additional water is added to compensate for a loss in workability (with a REF water to cement ratio $=0.5)$, the chloride ingress in uncracked SAP mortar is higher than in REF mortar;

- The chloride ingress in unhealed cracked specimens is higher in SAP specimens than in REF specimens as a possible consequence of the incomplete immediate sealing of the studied SAP particles and the larger air void content;

- The chloride ingress in cracked and subsequently healed specimens is lower than in unhealed specimens;

- At early ages the chloride penetration in cracked and healed SAP specimens is lower and at later ages the influence of a crack on the chloride ingress is reduced compared to cracked and healed REF specimens.
REF (healed)

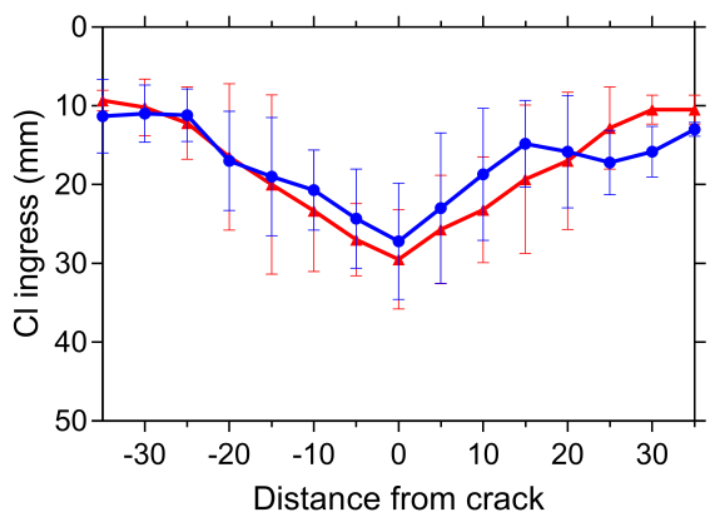

SAP (healed)

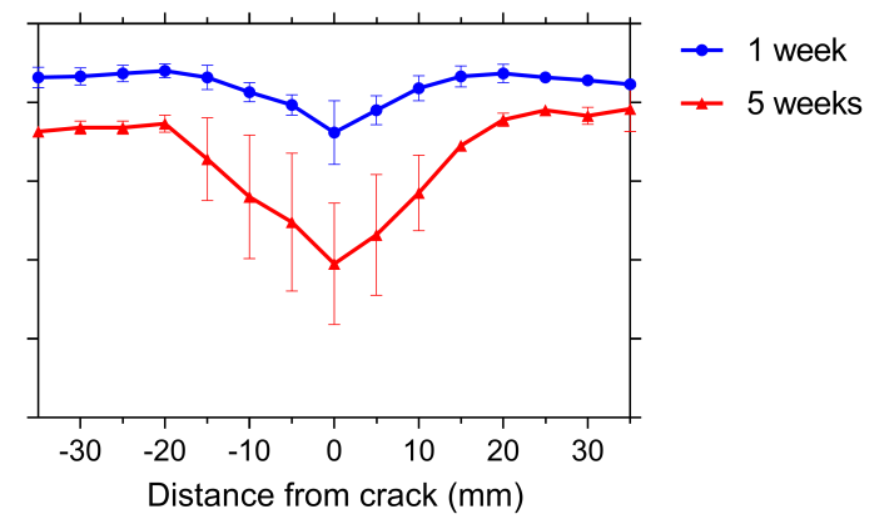

Fig. 7. Chloride ingress after 1 week and 5 weeks of saturation in a chloride solution of REF and SAP specimens which were not healed prior to contact with the chloride solution. 
This research was supported by a grant (19SCIP-B103706-05) from the Construction Technology Research Program funded by the Ministry of Land, Infrastructure and Transport of the Korean government. N. Lampens and T. Stulemeijer from the Magnel Laboratory of Concrete Research are thanked for their technical support during the execution of the tests. TRADECC and ENCI are thanked for their generous donation of CFRP, respectively cement.

\section{References}

1. C.-p. Gu, G. Ye, W. Sun. A review of the chloride transport properties of cracked concrete: experiments and simulations. Journal of Zhejiang UniversitySCIENCE A. (2015);16(2):81-92.

2. B. Šavija, E. Schlangen. Chloride ingress in cracked concrete-a literature review. Advances in modeling concrete service life: Springer; 2012. p. 133-42.

3. M. Maes, K. Van Tittelboom, N. De Belie. The efficiency of self-healing cementitious materials by means of encapsulated polyurethane in chloride containing environments. Construction and Building Materials. (2014);71:528-37.

4. P. Van den Heede, B. Van Belleghem, M. A. Pereira Gomes de Araújo, J. L. Garcia Feiteira, N. De Belie. Screening of different encapsulated polymer-based healing agents for chloride exposed self-healing concrete using chloride migration tests. (2018) $\mathrm{KEY}$ ENGINEERING MATERIALS. (2018).

5. B. Van Belleghem, P. Van den Heede, K. Van Tittelboom, N. De Belie. Quantification of the service life extension and environmental benefit of chloride exposed self-healing concrete. (2017) MATERIALS. (2017).

6. Y. Ç. Erşan, K. Van Tittelboom, N. Boon, N. De Belie. Nitrite producing bacteria inhibit reinforcement bar corrosion in cementitious materials. Scientific reports. (2018);8(1):14092.

7. D. Snoeck, P. Dubruel, N. De Belie. Superabsorbent polymers to prevent water movement in cementitious materials. INTERNATIONAL JOURNAL OF $3 R^{\prime} S$. (2012);3(3):432-40.

8. D. Snoeck, S. Steuperaert, K. Van Tittelboom, P. Dubruel, N. De Belie. Visualization of water penetration in cementitious materials with superabsorbent polymers by means of neutron radiography. Cement and Concrete Research. (2012);42(8):1113-21.

9. D. Snoeck, J. Dewanckele, V. Cnudde, N. De Belie. $\mathrm{X}$-ray computed microtomography to study autogenous healing of cementitious materials promoted by superabsorbent polymers. Cement and Concrete Composites. (2016);65:83-93.

10. M. T. Hasholt, O. M. Jensen. Chloride migration in concrete with superabsorbent polymers. Cement and Concrete Composites. (2015);55:290-7.

11. H. Beushausen, M. Gillmer, M. Alexander. The influence of superabsorbent polymers on strength and durability properties of blended cement mortars. Cement and Concrete Composites. (2014);52:73-80.

12. T. Van Mullem, E. Gruyaert, B. Debbaut, R. Caspeele, N. De Belie. Novel active crack width control technique to reduce the variation on water permeability results for self-healing concrete. Construction and Building Materials. (2019);203:541-51.

13. T. Van Mullem, K. Van Tittelboom, E. Gruyaert, R. Caspeele, N. De Belie, editors. Development of an improved cracking method to reduce the variability in testing the healing efficiency of self-healing mortar containing encapsulated polymers. Concrete Repair, Rehabilitation and Retrofitting (ICCRRR2018); 2018: EDP Sciences.

14. E. Gruyaert, B. Debbaut, D. Snoeck, P. Díaz, A. Arizo, E. Tziviloglou, et al. Self-healing mortar with $\mathrm{pH}$-sensitive superabsorbent polymers: testing of the sealing efficiency by water flow tests. Smart Materials and Structures. (2016);25(8):084007.

15. E. Tziviloglou, V. Wiktor, J. Wang, K. Paine, M. Alazhari, A. Richardson, et al., editors. Evaluation of experimental methodology to assess the sealing efficiency of bacteria-based self-healing mortar: round robin test. RILEM Conference on Microorganisms-Cementitious Materials Interactions; 2016: RILEM.

16. A. Mignon, D. Snoeck, D. Schaubroeck, N. Luickx, P. Dubruel, S. Van Vlierberghe, et al. pH-responsive superabsorbent polymers: A pathway to self-healing of mortar. Reactive and Functional Polymers. (2015);93:68-76.

17. W. Jin, Y. Yan, H. Wang. Chloride diffusion in the cracked concrete. Fracture Mechanics of Concrete and Concrete Structures-Assessment, Durability, Monitoring and Retrofitting. (2010):880-6. 